\title{
GCU
}

Glasgow Caledonian

University

University for the Common Good

\section{Parental perspectives on negotiations over diet and physical activity: how do we involve parents in adolescent health interventions?}

Shaw, Sarah; Simao, Sara Correia; Jenner, Sarah; Lawrence, Wendy T.; Woods-Townsend, Kathryn; Vogel, Christina A.; Farrell, David; Inskip, Hazel; Baird, Janice; Morrison, Leanne; Barker, Mary; Strömmer, Sofia T.; EACH-B Study Group

Published in:

Public Health Nutrition

DOI:

$10.1017 / S 1368980021000458$

Publication date:

2021

Document Version

Author accepted manuscript

Link to publication in ResearchOnline

Citation for published version (Harvard):

Shaw, S, Simao, SC, Jenner, S, Lawrence, WT, Woods-Townsend, K, Vogel, CA, Farrell, D, Inskip, H, Baird, J, Morrison, L, Barker, M, Strömmer, ST \& EACH-B Study Group 2021, 'Parental perspectives on negotiations over diet and physical activity: how do we involve parents in adolescent health interventions?', Public Health Nutrition, vol. 24, no. 9, pp. 2727-2736. https://doi.org/10.1017/S1368980021000458

\section{General rights}

Copyright and moral rights for the publications made accessible in the public portal are retained by the authors and/or other copyright owners and it is a condition of accessing publications that users recognise and abide by the legal requirements associated with these rights.

Take down policy

If you believe that this document breaches copyright please view our takedown policy at https://edshare.gcu.ac.uk/id/eprint/5179 for details of how to contact us. 
1 Parental perspectives on negotiations over diet and physical activity: how do we involve parents in adolescent health interventions?

3

4 Shaw, $\mathrm{S}^{1,2}$, Correia Simao, $\mathrm{S}^{1,2}$, Jenner, $\mathrm{S}^{1}$, Lawrence, $\mathrm{WT}^{1,2}$, Woods-Townsend, $\mathrm{K}^{2,3}$, Vogel, $5 \mathrm{CA}^{1,2}$, Farrell, $\mathrm{D}^{2,4}$, Inskip, $\mathrm{H}^{1,2}$, Baird, $\mathrm{J}^{1,2}$, Morrison, $\mathrm{L}^{5,6}$, Barker, $\mathrm{M}^{1,2}$, Strömmer, $\mathrm{ST}^{1,2}$ and the 6 EACH-B study group.

$7{ }^{1} \mathrm{MRC}$ Lifecourse Epidemiology Unit, University of Southampton, Southampton General 8 Hospital, Southampton, UK

${ }^{2}$ NIHR Southampton Biomedical Research Centre, University of Southampton and University Hospital Southampton NHS Foundation Trust, Southampton, UK

$11{ }^{3}$ Southampton Education School, Faculty of Social Sciences, University of Southampton, Southampton, UK

${ }^{4}$ School of Computing, Engineering and Built Environment, Glasgow Caledonian University, Glasgow, UK

${ }^{5}$ Centre for Clinical and Community Applications of Health Psychology, Southampton, UK

${ }^{6}$ Primary Care and Population Sciences, Southampton, UK

Corresponding author: Sarah Shaw, MRC Lifecourse Epidemiology Unit, University of Southampton, Southampton General Hospital, Southampton SO16 6YD.

Tel: +44 (0)2380 764043

Email: ss@mrc.soton.ac.uk

Short title: Parents and adolescent health interventions

Acknowledgements: In addition to the named authors, the EACH-B study group consists of 
Lovelock, Lisa Bagust. We thank Daniella Watson for her assistance with conducting the interviews.

Financial Support: This paper presents independent research from EACH-B funded by the National Institute for Health Research (NIHR) under its Programme Grants for Applied Research Programme (Reference Number RP-PG-0216-20004). This research and the authors of this paper are also supported by the following funding sources UK Medical Research Council (MC_UU_12011/4); National Institute for Health Research Southampton Biomedical Research Centre; Wessex Heartbeat and Public Health England. The views expressed in this publication are those of the author(s) and not necessarily those of the National Health Service, the National Institute for Health Research, the UK Department of Health and Social Care.

Conflict of Interest: CV has a non-financial research relationship with a food retail company and maintains independence in all evaluation activities. This article, however, is not related to this relationship. All other authors have no conflicts of interest to declare.

Authorship: MEB and HMI formulated the research questions. MEB, STS and KWT designed the research study, with inputs from HMI, JB, WTL, CV and DF. SS, STS, SJ conducted the qualitative interviews. The thematic analysis was conducted by SS, SCS, SJ and STS with guidance from WTL, LM, MEB. All authors played a role in interpreting the results and all approved the final manuscript. This work was conducted as part of the EACH-B study.

Ethical Standards Disclosure: This study was conducted according to the guidelines laid down in the Declaration of Helsinki and all procedures involving research study participants were approved by the University of Southampton Faculty of Medicine Ethics Committee [Ethics Number: 30054]. Written informed consent was obtained from all participants 


\section{Abstract}

Objective: To identify the ways in which parental involvement can be incorporated into interventions to support adolescent health behaviour change.

Design: Data from semi-structured interviews were analysed using inductive thematic analysis.

Setting: Southampton, Hampshire, UK.

Participants: A convenience sample of 24 parents of adolescents.

Results: Parents consider themselves to play an important role in supporting their adolescents to make healthy choices. Parents saw themselves as gatekeepers of the household and as role models to their adolescents but recognised this could be both positive and negative in terms of health behaviours. Parents described the changing dynamics of the relationships they have with their adolescents because of increased adolescent autonomy. Parents stated that these changes altered their level of influence over adolescents' health behaviours. Parents considered it important to promote independence in their adolescents, however, many described this as challenging because they believed their adolescents were likely to make unhealthy decisions if not given guidance. Parents reported difficulty in supporting adolescents in a way that wasn't viewed as forceful or pressuring.

Conclusions: When designing adolescent health interventions that include parental components, researchers need to be aware of the disconnect between public health recommendations and the everyday reality for adolescents and their parents. Parental involvement in adolescent interventions could be helpful but needs to be done in a manner that is acceptable to both adolescents and parents. The findings of this study may be useful to inform interventions which need to consider the transitions and negotiations which are common in homes containing adolescents.

\section{Keywords:}

Adolescent; Health behaviours; Parents; Qualitative methods. 


\section{Introduction}

Adolescence is a period often characterised by poor health behaviours including high intake of energy-dense, nutrient-poor food and low levels of physical activity. ${ }^{(1)}$ In the UK, many adolescents fail to meet Public Health England's recommendations for a healthy diet and physical activity levels. Only $8 \%$ of UK adolescents aged between $11-18$ years eat five portions of fruit and vegetables a day, ${ }^{(2)}$ and only $15 \%$ of boys and $8 \%$ of girls, aged $13-15$ years, carry-out one hour of moderate to vigorous activity per day. ${ }^{(3)}$ Adolescents are the parents of future generations. Thus, intervening during adolescence to improve diet and physical activity has the potential for triple benefit: to the adolescent in the here and now, to the future health of the adolescent, and to the health of the adolescent's future offspring. ${ }^{(4,5)}$ Although this age group has been identified as a priority group for health improvement, few interventions aiming to improve adolescent diet and physical activity levels show long-term effectiveness. ${ }^{(6-9)}$

Adolescence is a period of dramatic physical and psychosocial change. ${ }^{(10)}$ Adolescents experience a desire for increased levels of autonomy over decisions in their life. ${ }^{(11)}$ This newfound independence, coupled with increased exposure to factors outside of the family home, can lead to the participation in health-compromising behaviours. ${ }^{(5)}$ Nonetheless, parents still play an influential role in adolescents' day-to-day lives even though capacity for decision-making is increasing.

Health behaviour interventions targeting adolescents have been implemented using a number of different approaches with varying degrees of success. ${ }^{(6-8,12)}$ It is argued that many of these health interventions are unsuccessful because they do not address adolescents' desire to feel respected, and fail to offer opportunities for adolescents to exercise autonomy over their health behaviours. ${ }^{(9,13,14)}$

Evidence indicates that interventions targeting children and adolescents which also involve parents have the potential to be successful, but results have varied. ${ }^{(7,8,15,16)}$ Parents have been incorporated into interventions using multiple 'indirect' and 'direct' strategies. ${ }^{(15)}$ Indirect parental engagement strategies have been more commonly used in intervention studies to date and often include delivering health information to parents via newsletters and web-platforms. Direct strategies have included parental attendance at educational and 
coaching sessions. Studies including such direct strategies are limited and may be subject to bias, as such selection bias where more highly motivated parents participate.

The important role parents play in their adolescents' lives, if harnessed appropriately, could promote engagement with interventions outside of the immediate delivery setting. However, there is no clear consensus on what type of parental involvement is most effective. ${ }^{(15)}$ In addition, little is known about parental views of the most acceptable ways of involving them in health interventions targeting their adolescents.

This study therefore adopted a qualitative approach to explore three research questions:

\section{Methods} Design

1) How do parents view their role in supporting their adolescents to eat healthily and be more physically active?

2) What factors influence the way in which parents choose to support their adolescents?

3) How can we help parents support their adolescents to make healthier choices?

This exploratory qualitative study formed part of the developmental work for the Engaging Adolescents in CHanging Behaviour (EACH-B) study. The EACH-B study is a multi-component intervention aiming to support adolescents to engage in healthy diet and physical activity behaviours. ${ }^{(17)}$ The development of the EACH-B intervention was conducted using a Person Based Approach which adopts user-centred methods to design and refine interventions. This involves in-depth qualitative interviews with stakeholders in order to ensure interventions are appropriate to the target population. ${ }^{(18)}$ Reporting of this study follows COnsolidated criteria for REporting Qualitative research (COREQ) recommendations. ${ }^{(19)}$

\section{Study Participants}

A convenience sample of parents, who had at least one adolescent attending secondary school, was recruited from those who were part of an email list following their adolescent's visit to LifeLab. Lifelab is an educational facility based at Southampton General Hospital, UK and is primarily attended by students from Hampshire based secondary schools between the ages of 11-18 years. Parents were sent an email explaining the details of the study. If 
they were happy to participate, they were asked to reply to the study email. Those who agreed were later contacted by a member of the research team to discuss the details of the study and organise a suitable time for the interview. Parents were excluded if they did not speak English or if they did not have an adolescent aged 11-18 years who was attending secondary school. Prior to participating in the interviews, all parents provided informed written consent.

\section{Setting}

The study was conducted in 2018 in Southampton, a large city on the south coast of England, ranked the 67th most deprived of the 326 local authorities in England. ${ }^{(20)}$ The interviews were conducted in locations that were convenient for the study participants, including places of work, home and over the telephone for the individual interviews. Group interviews were conducted at a hospital evening event for parents.

\section{Procedure}

Four women researchers were involved in the interviews; SS (PhD student and research assistant) and STS (Post-doctoral research fellow) conducted the interviews. SJ (MSc student and research assistant) and $\mathrm{D}$. Watson (PhD student and research assistant) acted as observers in the interviews. All researchers received training in conducting qualitative interviews; SS and STS had previous experience of conducting qualitative research. The researchers were not known to the participants prior to correspondence about the study. Each participant completed a brief demographic questionnaire asking their age, gender, ethnicity and level of education. They were made aware that the research team was aiming to develop an intervention to improve diet and physical activity in adolescents. A semistructured discussion guide was designed to explore parents' views of their adolescent's health and lifestyle, as well as factors which make it difficult for them to engage in healthy behaviours (Table 1). All interviews were audio-recorded and transcribed verbatim either by one of the authors (SJ) or by a professional transcription company.

\section{Analysis}

Interview recordings were analysed thematically using NVivo software (Version 12) (QSR International, version 12) to manage the data. Researchers familiarised themselves with the data by reading the interview transcripts and listening to the recordings. Inductive thematic 
173 analysis was conducted following established guidelines. ${ }^{(21)}$ Three researchers (SS, SJ, SCS) worked independently to create initial codes in NVivo. After three transcripts were coded, the researchers met to discuss the similarities and differences between the codes. Codes were then organised into themes and sub-themes to create an initial coding frame. The coding frame was refined through coding of all transcripts (SS, SJ, SCS) until a sixth, final comprehensive coding frame was agreed (Figure 1). Themes and sub-themes were compiled together with verbatim quotations and agreed with senior members of the research team (STS, LM, WTL, MEB). This approach was conducted in line with a relativist ontological and subjective epistemic position, following the belief that reality is a matter of individual perspective and based on personal experience and insight. ${ }^{(22)}$

Researchers agreed that data saturation had been reached when no new topics arose from the final transcripts. Appropriate transcript excerpts were selected and agreed on by the researchers in order to accurately represent the meaning of each theme and sub-theme. The relationships between the themes were discussed by the research team and visualised by creating a thematic map.

\section{$\underline{\text { Results }}$}

A total of 24 parents participated in this study; 18 in individual interviews and six in two focus group discussions, each consisting of three participants. Each interview lasted approximately 20-45 minutes. Six individual interviews were conducted via telephone; all other interviews were conducted face-to-face. All participants were women. The majority (71\%) were aged between $40-49$ years and $96 \%$ identified as white (Table 2 ).

Six themes, consisting of multiple sub-themes, were identified by the analysis. Figure 1 shows the final coding frame which was used for the thematic analysis. Each theme is described alongside illustrative quotes from the interviews. Figure 2 shows the relationships between themes one to five and how they centre around the parents' sense of control.

Themes

\section{My role in maintaining my adolescent's heath}

Parents described exerting authority over their households in several ways, including being in control of food preparation and rules for behaviour within the household. 
"I am the one who controls the meals I guess, in the sense that I cook them, I put them on the table"- [Parent Group 1]

Parents recognised that promoting independence and encouraging adolescents to make some of their own choices is an important aspect of their parenting role.

"More recently I try and give my daughter a bit more control over her food, not because she's requested it but I guess this comes from a kind of teaching background"- [Parent Interview 1]

Even though parents viewed promoting independence in their adolescents as important, they described a reluctance to step back fully from their traditional parental role. They discussed ways in which they attempted to be attentive and supervise their adolescent whilst trying not to be directly involved. This involved checking their homework and food choices when out of the home using mobile apps and monitoring their social media use.

"I try to police it, he's got like an Instagram account so I've set one up for me and I can follow him, so I know what he's up to. He's got a Facebook account and again I'm his friend on Facebook so again I can kind of see what he's up to"- [Parent Interview 2]

Parents described themselves as role models to their adolescents but acknowledged they did not always model healthy behaviours. They described modelling behaviours in relation to their own actions as well as the actions of other parents.

"If you've got inactive parents, your children aren't gonna be active"- [Parent Interview 6]

\section{What I think about health}

As depicted in Figure 2, parents recognised that their personal perspective of health influenced how they viewed their role in promoting health in their adolescent. Many parents discussed their own or family members' experiences of ill health and participation in healthy behaviours. They also outlined the ways in which past experiences influenced their current thoughts about health and leading a healthy lifestyle.

"So health is quite a complex thing in our family. We've had, well I've had, particular periods of extremely bad health, and so therefore being healthy has been something 
that we all take quite seriously in an attempt to counteract that as much as we possibly can."- [Parent Interview 1]

Parents described the importance of taking steps to ensure their families' good health, but also acknowledged that this is not always a priority for themselves or their adolescent.

"What do you guys tend to do, to be healthy? - [Interviewer]

Honestly, we don't do enough, we don't do a lot."- [Parent Group 2]

"I personally think it's really important, but it's not just about eating. I think it's about exercise as well, and doing them both."- [Parent Interview 6]

Parents described barriers to leading a healthy lifestyle and how these justified why healthy habits are not enforced in the family setting.

"You've also got to remember that, you know, some of them [other parents] are living on a very, very tight budget. It is cheaper to buy convenience food. So much easier to

\section{My adolescent wants...}

Parents believed that an important factor in determining adolescents' food choices was convenience and accessibility. They saw their adolescents as wanting foods to be prepared for them or for it to be very simple to prepare themselves. Parents believed that adolescents would not go out of their way to make healthy food choices but are open to healthy choices if they are available and convenient.

"So, when he comes home from school, he definitely wants food. But he is happy for me to say $t$ Interview 13]

Parents suggested adolescents were not motivated by health messages which are often perceived as boring. They described their adolescents as being willing to participate in healthy lifestyle behaviours as long as there was a reason for doing so that was not just health.

"In terms of sort of physical exercise, the dog has made a huge, huge difference to us and we enjoyed the sunshine, we had time together and walked the dog"- [Parent Interview 9] 
Parents emphasised that their adolescents would only engage with activities they enjoyed rather than those they classed as boring.

"They've gotta enjoy it. You've gotta find something they enjoy"-[Parent Interview 6]

Parents recognised the pressure adolescents feel to be accepted and fit in with their peers, and how this can negatively affect their diet and exercise choices.

"Well my kids have said, and I can well believe this, that they do it to be with other kids that are buying food. And they don't want to feel left out, that they're not doing that kind of thing. So I think it's peer pressure, to be going, to be getting that stuff." [Parent Group 2]

Conversely, friends and peers could also have a positive influence regarding being healthy and active.

"She's got some friends who like running... I think parents have got them into cross country club and running clubs, and so in their little group that's acceptable, 'cause there's some kids who do it. I just think it needs a couple of them to be brave and they can then set the norm"- [Parent Interview 5]

Parents believed that when adolescents had autonomy over their health decisions, they made less healthy choices. They described their adolescent's tendency to select unhealthy foods when they were not around to guide these decisions.

"When she first went to the senior school, I gave her money on her account ... she

Parents also believed that their adolescent needed prompting to be physically active.

"If my son had the choice, he would much rather stay in front of a screen" - [Parent

Parents recognised the importance of adolescents having the right individuals to provide support and encourage healthy behaviours. Parents specified that not everyone can fulfil these roles and that these people need to be acceptable to their adolescents.

"It [giving health advice] shouldn't be done by someone at school. I mean it can be done by someone in the school, but not by a teacher who they wouldn't respect."[Parent Interview 3] 
Figure 2 illustrates that parents recognised a number of factors that they considered to be outside their control that influenced what their adolescent wanted and how they viewed their role in promoting adolescent health. Parents perceived that schools did not always provide opportunities for their adolescents to participate in healthy behaviours but appeared to feel there was nothing they could do about it. "She's doing food tech at school and has learned to make a few meals, none of them particularly healthy, interestingly, you know chicken goujons, pizza, muffins, you know they've all been those sorts of things. I think its quick food, because they have such short lessons. They have to teach you know, it's not nutrition they're learning." [Parent Interview 1]

Parents were aware that technology such as smartphones and video games are valued by adolescents and felt that these got in the way of adolescents leading a healthy lifestyle. "Her activity levels are low, way too low. And for me, it's the phone. I have real, real issues with the mobile phone. Huge issues"- [Parent Group 3]

"We had a complete break-down, because we were going on holiday and she was not going to have internet. 'I've had a forty-day streak with somebody, I can't.'"'[Parent Group 2]

\section{Negotiating Control}

Parents discussed the changing dynamics of control between them and their adolescent, resulting in a culture of compromise between the parent and adolescents which was influenced by several factors inside and outside the home (Figure 2). Parents suggested that their adolescent would ignore or rebel against strict household rules, so they would sometimes relax or modify these in an attempt to maintain control and establish an acceptable compromise.

"If you're too strict with them about what they can eat, then they'll rebel." - [Parent "I've learnt that the more you badger, the worse it gets"- [Parent Interview 10]

As adolescents gained exposure to factors outside of the family unit, there could be increasing conflict between what is normal for the family and what is normal for others. 
Parents described changes in their adolescents' eating habits which can make mealtimes challenging. To avoid conflict, they provided food they know will be acceptable even if this means cooking less healthy meals.

Parents also described the challenges of talking to their adolescent about health behaviours. "I mean, there are times when he refuses things like pasta and rice... and sometimes I end up giving him chips." - [Parent Interview 13]

"Your mum and dad saying, "Oh, this is what you ought to do," it's gonna be like, no. I don't think they generally take very kindly... or a lot of them don't."- [Parent Interview 10]

"I think the most important thing to us is just trying and keep talking with them and I

Parents reported a reciprocal influence in their interactions with their adolescents. While parents could encourage adolescents to eat healthier and be more active, they could also be influenced by adolescents to pursue a healthier lifestyle themselves.

"On the days when I haven't gone for a run, they go, "Oh, hang on a minute, you're telling me to go, but you haven't been. Actually, we could do this together."-

[Parent Inte

\section{What parents think could help support adolescent health}

Parents stated that their adolescents appreciated rewards and thought that this could be a useful way to encourage engagement with healthy behaviours. Parents recognised that technology was important to their adolescents and that findings ways in which it could be used to benefit health was important.

"My daughter's recently been doing virtual medals, where you run a $5 K$ or something, and then you claim your medal at the end of it, and it comes through the post."[Parent Group 2]

Parents also highlighted that it was important to make participating in healthy behaviours appealing to their adolescents. 
When asked how they would like to be involved in health interventions, some parents suggested that facilitating the link between the parent and the adolescent might help the them find ways to support with healthy behaviour changes.

Others stated that difficulties might arise when trying to engage parents with this sort of health intervention. adolescents might be challenging as they valued their privacy.

\section{Discussion}

355 This paper identified an overarching theme describing the changing dynamics between parents and adolescents which concern shifting perceptions of control. This was at the centre of how parents viewed their role in supporting their adolescents to eat healthily and be physical active. Parents recognised that their role in supporting these behaviours was reducing as their adolescents' autonomy and independence increased. Parents described negotiations with their adolescents as playing a role in determining the healthiness of their adolescents' food choices and activity levels. Parents found that their attempts to guide and advise their adolescents were poorly received and often caused a breakdown in communication.

Parents also recognised several external factors that presented barriers to healthy behaviours in their adolescents and these also influenced how they viewed their role in supporting healthy behaviours.

367 The parents we spoke to felt their adolescents lacked the ability to self-regulate their behaviours and, if left to their own devices, would not be physically active and would choose unhealthy food, especially in environments where such foods were readily available. 
371 from an early age, adolescents tended towards unhealthy behaviours such as eating foods

372 high in fat, salt and sugar and low physical activity levels.

373 Parents recognised that interventions need to be appealing, to fit into their adolescents' 374 lives, and certainly not be viewed as boring. They highlighted that interventions focusing solely on health were unlikely to engage adolescents. Parents also stated that interventions containing parental components needed to fit into their lives otherwise they risked being side-lined as they will not be viewed as a priority in parents' busy lives.

\section{Comparisons with previous literature}

In line with the 'negotiating control' theme identified in this study, previous qualitative research exploring parent and adolescent attitudes towards sugar-sweetened beverage consumption and screen time has described regular disagreements between parents and adolescents about everyday decisions that influence the behaviours of the family in the household. ${ }^{(23)}$ This research recognised that any adolescent interventions must acknowledge this dynamic in order to be effective. ${ }^{(23)}$ Other qualitative work has also described the view held by parents that controlling the home food environment is one of the most effective methods of promoting healthy food choices by their adolescents. ${ }^{(23,24)}$ However, evidence suggests that this practice may vary by socio-economic status, a factor that was not explored in the current study. ${ }^{(24)}$ A limitation of previous research is that it has only focused on specific dietary behaviours such as sugar-sweetened beverage consumption, while the current study focused on exploring parents' views of the more complex behaviour of overall food choice. Parents have also previously described a lack of control when it comes to countering the negative influence of peers on the health behaviours of their children and feeling lower levels of control over other household activities such as screen time. ${ }^{(23,25)}$ Other authors have identified open communication between parents and adolescents as an important tool for effectively supporting weight management interventions for obese and overweight adolescent populations. ${ }^{(25,26)}$ Parents in the current study recognised that communication with their adolescent was often difficult and "the more they badgered" their adolescent the less likely it was for their advice to be accepted. This suggests that training for parents in effective communication skills may be an important strategy to include in interventions for non-clinical, as well as clinical, populations. This is supported by 
other qualitative research with parents and adolescents that also proposes positive communication styles to be the most effective in promoting healthy behaviours. ${ }^{(23)}$

\section{Implications for public health}

Parents described the changing dynamics of their relationships with their adolescents as a major influence on how they provided support, with negotiations seeming to be part of everyday life. Branje describes these negotiations as a reorganisation of the parentadolescent relationship from one that is vertical, with the parent in a position of power, to one that is horizontal, where power is more equally balanced. ${ }^{(27)}$ As part of these negotiations, parents appeared to value their role in promoting independence in their adolescents, though doubted that their adolescents would participate in healthy behaviours if left to their own devices. Previous research highlights that approaches to enhance autonomy are more effective in promoting healthy eating in children and adolescents than more controlling strategies. ${ }^{(28)}$

To date, the majority of parental components in adolescent health interventions have used indirect, but overt, methods to encourage healthy behaviours in adolescents. Such methods have focused on providing information to parents using newsletters, tip sheets and nutrition and physical activity information sheets. ${ }^{(15)}$ Parents who took part in this study felt that they had less control over their adolescents' food and physical activity choices than when they were children. These findings highlight the importance of how the information provided as part of these interventions is converted by parents into practical support for the adolescent, if at all. It is suggested that direct methods such as parent training and information sessions may be more effective than indirect methods. ${ }^{(15)}$ However, parents themselves felt that such direct methods might be an ineffective way to engage other parents in interventions due to life pressures restricting their ability to attend such meetings. Participants reported that other parents might feel their lives were too busy and that some might feel that they had nothing to learn. ${ }^{(15)}$

Some parents in this study described how health behaviours, such as home cooking and participating in physical activity, had become normal in their families, having been established and practised for many years. Many parents felt that adolescents were open to 
eating healthy foods, at least at home, if they were convenient for the adolescent to access and eat. However, most parents still recognised significant challenges when attempting to encourage adolescents to consider swapping unhealthy behaviours for healthier choices. As described in the sub-theme 'schools don't always provide healthy options', parents viewed the food options that were often available on school premises as unhealthy and thought that adolescents would choice these options if they were available. Previous research has shown that the majority of food high in fat, salt and sugar which adolescents eat is consumed outside of the home. ${ }^{(29)}$ Parents in this study perceived that they had very little control over their adolescents food choices outside the home. Adolescents are bombarded with advertising and promotions which promote unhealthy food choices in these environments. ${ }^{(30)}$ Public health interventions to encourage more healthful food environments are likely to play a role in promoting healthy dietary choices in adolescents when they are away from the home environment. Adolescent autonomy and sense of social justice has previously been incorporated into an experimental study to highlight the role of manipulative food marketing and promote healthier dietary choices. ${ }^{(31)}$ Future health behaviour interventions may find incorporating similar techniques as a helpful way to raise adolescents awareness of unhealthy food environments and support them to be more critical of how environments shape their behaviours.

Future interventions should aim to equip parents with strategies to promote healthy autonomous behaviours. One such strategy may include facilitating effective communication between parents and adolescents. ${ }^{(32)}$ Communication strategies which were not forceful or pressuring have been found to be preferred by both parents and adolescents. ${ }^{(33)}$ This supports previous research which investigated the role of authoritarian and authoritative parenting styles in relation to adolescent eating behaviours. An authoritative parenting style, one that provides structured guidance and takes the views of the adolescent into consideration, has been shown to be positively associated with increased fruit and vegetable consumption and breakfast intake. ${ }^{(34)}$ Qualitative research shows that adolescents do not respond positively to authoritarian parenting styles, characterised by strict enforcement of parental rules with little input from the adolescent, as adolescents reported feeling urge to rebel by eating unhealthy foods if they felt they were being lectured by their parents. ${ }^{(35)}$ Parental communication that promotes autonomy 
in adolescents aligns with adolescents' desire to feel respected and have the potential to increase the effectiveness of interventions. ${ }^{(9)}$ One potential way of empowering parents with effective communication strategies could be through the delivery of Healthy Conversation Skills training. Healthy Conversation Skills offers a set of accessible, theorybased skills focusing on listening, reflecting and goal-setting. ${ }^{(36,37)}$ The use of such techniques may enable adolescents to feel that their views are being listened to, and feel more independent, while still allowing parents to guide their adolescents to identify their own health goals and explore ways of achieving them that they consider acceptable and feasible. ${ }^{(36,37)}$ Training in these skills may be more enticing to parents, than information training about healthy lifestyle behaviours, as the focus can be placed on building and fostering relationships between parents and adolescents rather than only focusing on health. This training has not previously been provided to parents but has been shown to be effective in primary health care settings. Providing Healthy Conversation Skills training via a digital platform may be one way to overcome the need for face-to-face training with parents, which has been a barrier to intervention delivery in previous studies. ${ }^{(38)}$

\section{Strengths and Limitations}

The qualitative interviews in this study have provided rich data on parental perspectives of adolescents' lives. This perspective has not often been considered when developing interventions that target adolescents. Despite the best efforts of the authors, it was not possible to recruit any fathers to participate in this study. This recruitment issue may be related to the increased parental involvement of mothers who often take on a traditional primary caregiver role within the family. The difficulty of recruiting fathers to participate in this type of research has been highlighted previously. ${ }^{(39,40)}$ It is likely that fathers have a different perspective on their adolescents' lives, and the benefit of including them in future studies would be significant. Most participants in this study were white (representative of locality) and were educated to upper secondary school standard or above. Interviews with more diverse groups of parents may have produced different data. The interpretation of the qualitative data presented in this paper is only one possible interpretation and will have been influenced by the experiences and beliefs of the research team. In order to ensure the research findings from this study fairly represented the views of the interviewees, a rigorous 
494 process was adopted that involved double-coding of data, with disagreements being

495 resolved through team discussions. The final interpretation of the data was agreed by all

496 team members after multiple discussions.

\section{Conclusions}

498 This study found that parents recognise and value the importance of promoting good health

499 behaviours in their adolescents but find doing so difficult due to the increasing lack of

500 influence they have over elements of their adolescents' lives. When designing adolescent

501 health interventions that include parental components, researchers need to be aware of the

502 disconnect between public health recommendations and the everyday reality for

503 adolescents and their parents. This research may be useful to inform interventions which

504 need to consider the transitions and negotiations which are common in homes containing

505 adolescents. Future qualitative research using dyadic interviews, conducted with both

506 parents and adolescents, may provide insight into the shared experiences of the changing

507 levels of control in their lives and inform how, and when, to deliver a communication

508 intervention. Researchers designing these health interventions need to recognise that a 'one

509 size fits all' approach is unlikely to produce successful long-term health behaviour change. 
512 1. Bates B, Cox L, Nicholson S et al. (2016) National Diet and Nutrition Survey results from Years 5 and 6 (combined) of the Rolling Programme (2012/2013 - 2013/2014). London: PHE.

514 2. Public Health England (2018) National Diet and Nutrition Survey Results from Years 7 and 8 (combined) of the Rolling Programme (2014/2015 to 2015/2016). London.

516 3. NHS Digital (2016) Health Survey for England 2015 Physical Activity in Children. London.

517 4. Barker M, Dombrowski SU, Colbourn T et al. (2018) Intervention strategies to improve $518 \quad$ nutrition and health behaviours before conception. The Lancet 391, 1853-1864.

5. Patton GC, Sawyer SM, Santelli JS et al. (2016) Our future: a Lancet commission on adolescent health and wellbeing. The Lancet, 387, 2423-2478.

6. Calvert S, Dempsey RC Povey R (2019) Delivering in-school interventions to improve dietary behaviours amongst 11- to 16-year-olds: A systematic review. Obesity Reviews 20, 543-553.

7. Rose T, Barker M, Maria Jacob C et al. (2017) A Systematic Review of Digital Interventions for Improving the Diet and Physical Activity Behaviors of Adolescents. The Journal of adolescent health : official publication of the Society for Adolescent Medicine 61, 669-677.

8. Stice E, Shaw H Marti CN (2006) A meta-analytic review of obesity prevention programs for children and adolescents: the skinny on interventions that work. Psychol Bull 132, 667-691.

9. Yeager DS, Dahl RE Dweck CS (2018) Why Interventions to Influence Adolescent Behavior Often Fail but Could Succeed. Perspectives on psychological science : a journal of the Association for Psychological Science 13, 101-122.

10. World Health Organization (2014) Health for the World's Adolescents. A second chance in the second decade. Geneva.

11. Stangor C (2014) Adolescence: Developing Independence and Identity. In Introduction to Psychology. Boston: FlatWorld.

12. Chen JL \& Wilkosz ME (2014) Efficacy of technology-based interventions for obesity prevention in adolescents: a systematic review. Adolesc Health Med Ther 5, 159-170.

13. Bassett R, Chapman GE Beagan BL (2008) Autonomy and control: the co-construction of adolescent food choice. Appetite 50, 325-332.

14. Bryan CJ, Yeager DS, Hinojosa CP et al. (2016) Harnessing adolescent values to motivate healthier eating. Proceedings of the National Academy of Sciences 113, 10830.

15. Hingle MD, O'Connor TM, Dave JM et al. (2010) Parental involvement in interventions to improve child dietary intake: a systematic review. Prev Med 51, 103-111.

16. Van Lippevelde W, Verloigne M, De Bourdeaudhuij I et al. (2012) Does parental involvement make a difference in school-based nutrition and physical activity interventions? A systematic review of randomized controlled trials. Int J Public Health 57, 673-678.

17. ISRCTN Registry (2019) Engaging adolescents in changing behaviour: a programme of research to improve the diets and physical activity levels of adolescents. https://doi.org/10.1186/ISRCTN74109264 (accessed 24/02/2020

18. Yardley L, Morrison L, Bradbury K et al. (2015) The person-based approach to intervention development: application to digital health-related behavior change interventions. J Med Internet Res 17, e30. 
19. Tong A, Sainsbury P Craig J (2007) Consolidated criteria for reporting qualitative research (COREQ): a 32-item checklist for interviews and focus groups. International Journal for Quality in Health Care 19, 349-357.

20. Southampton City Council S (2015) Index of Multiple Deprivation (2015) Analysis of overall changes since 2010.

21. Braun V \& Clarke V (2006) Using thematic analysis in psychology. Qualitative research in psychology 3, 77-101.

22. Braun V \& Clarke V (2013) Successful qualitative research. A practical guide for beginners. London: SAGE.

23. Hattersley LA, Shrewsbury VA, King LA et al. (2009) Adolescent-parent interactions and attitudes around screen time and sugary drink consumption: a qualitative study. The international journal of behavioral nutrition and physical activity 6, 61-61.

24. Roth-Yousey L, Chu YL Reicks M (2012) A Qualitative Study to Explore How Parental Expectations and Rules Influence Beverage Choices in Early Adolescence. Journal of Nutrition Education and Behavior 44, 644-652.

25. Azar KMJ, Halley M, Lv N et al. (2020) Differing views regarding diet and physical activity: adolescents versus parents' perspectives. BMC pediatrics 20, 137-137.

26. Hadley W, McCullough MB, Rancourt D et al. (2015) Shaking up the system: the role of change in maternal-adolescent communication quality and adolescent weight loss. Journal of pediatric psychology 40, 121-131.

27. Branje S (2018) Development of Parent-Adolescent Relationships: Conflict Interactions as a Mechanism of Change. Child Development Perspectives 12, 171-176.

28. Baumrind D (2005) Patterns of parental authority and adolescent autonomy. New Dir Child Adolesc Dev, 61-69.

29. Toumpakari Z, Haase AM Johnson L (2016) Adolescents' non-core food intake: a description of what, where and with whom adolescents consume non-core foods. Public Health Nutr 19, 1645-1653.

30. Truman E \& Elliott C (2019) Identifying food marketing to teenagers: a scoping review. International Journal of Behavioral Nutrition and Physical Activity 16, 67.

31. Bryan CJ, Yeager DS Hinojosa CP (2019) A values-alignment intervention protects adolescents from the effects of food marketing. Nature human behaviour 3, 596-603.

32. Tu AW, Watts AW, Chanoine JP et al. (2017) Does parental and adolescent participation in an e-health lifestyle modification intervention improves weight outcomes? BMC Public Health 17,352 .

33. Shrewsbury VA, King LA, Hattersley LA et al. (2010) Adolescent-parent interactions and communication preferences regarding body weight and weight management: a qualitative study. International Journal of Behavioral Nutrition and Physical Activity 7, 16.

34. Sleddens EFC, Gerards S, Thijs C et al. (2011) General parenting, childhood overweight and obesity-inducing behaviors: a review. International Journal of Pediatric Obesity 6, E12-E27.

35. Krølner R, Rasmussen M, Brug J et al. (2011) Determinants of fruit and vegetable consumption among children and adolescents: A review of the literature. Part II: Qualitative studies. The International Journal of Behavioral Nutrition and Physical Activity, 8. 
36. Barker M, Baird J, Lawrence W et al. (2011) The Southampton Initiative for Health: a complex intervention to improve the diets and increase the physical activity levels of women from disadvantaged communities. J Health Psychol 16, 178-191.

37. Lawrence W, Black C, Tinati T et al. (2016) 'Making every contact count': Evaluation of the impact of an intervention to train health and social care practitioners in skills to support health behaviour change. J Health Psychol 21, 138-151.

38. Hammersley ML, Jones RA Okely AD (2016) Parent-Focused Childhood and Adolescent Overweight and Obesity eHealth Interventions: A Systematic Review and Meta-Analysis. J Med Internet Res 18, e203.

39. Davison KK, Gicevic S, Aftosmes-Tobio A et al. (2016) Fathers' Representation in Observational Studies on Parenting and Childhood Obesity: A Systematic Review and Content Analysis. Am J Public Health 106, e14-e21.

40. Panter-Brick C, Burgess A, Eggerman M et al. (2014) Practitioner review: Engaging fathers-recommendations for a game change in parenting interventions based on a systematic review of the global evidence. J Child Psychol Psychiatry 55, 1187-1212. 


\begin{tabular}{|l|l|}
\hline \multicolumn{1}{|c|}{ Interview Topic } & \\
\hline Health & $\begin{array}{l}\text { What does it mean to you to be healthy? } \\
\text { What kinds of things do you do to keep healthy? } \\
\text { How often do you and your adolescent talk about health and what it means to be } \\
\text { healthy? }\end{array}$ \\
\hline Parent Life & What kinds of things do you do to keep healthy? \\
\hline Family Life & $\begin{array}{l}\text { What is a typical day like for your family? } \\
\text { How does your family decide what to eat at home? } \\
\text { What kinds of things do you do with your adolescent to keep healthy? } \\
\text { What kinds of things do you encourage your adolescent to do to keep healthy? }\end{array}$ \\
\hline Your adolescent & What kinds of things does your adolescent like to eat? \\
\hline What kinds of activities does your adolescent engage in?
\end{tabular}




\begin{tabular}{|c|c|}
\hline Characteristic & n (\%) \\
\hline \multicolumn{2}{|l|}{ Age (vears) } \\
\hline $30-39$ & $2(8)$ \\
\hline $40-49$ & $17(71)$ \\
\hline $50-59$ & $5(21)$ \\
\hline \multicolumn{2}{|l|}{ Gender } \\
\hline Women & $24(100)$ \\
\hline Men & $0(0)$ \\
\hline \multicolumn{2}{|l|}{ Ethnicity } \\
\hline White & $23(96)$ \\
\hline Arabic & $1(4)$ \\
\hline \multicolumn{2}{|l|}{ Highest Qualification } \\
\hline Lower secondary education or below (GCSE) & $2(8)$ \\
\hline Upper secondary education (A-levels or equivalent) & $7(29)$ \\
\hline Post-secondary education (Higher National Diploma or equivalent) & $2(8)$ \\
\hline Bachelor's degree or above & $10(42)$ \\
\hline Other & $3(13)$ \\
\hline
\end{tabular}

613

614

615

616 


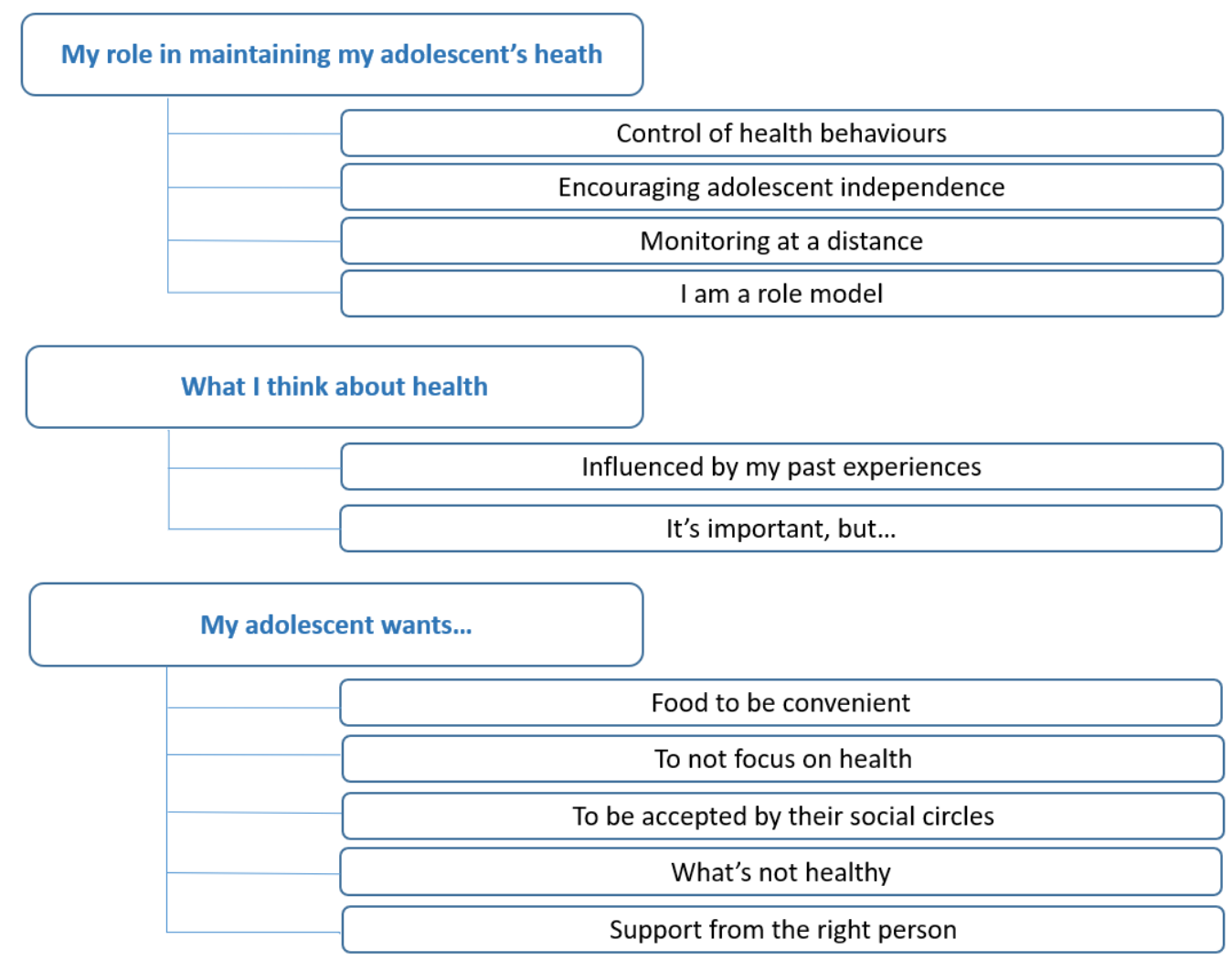

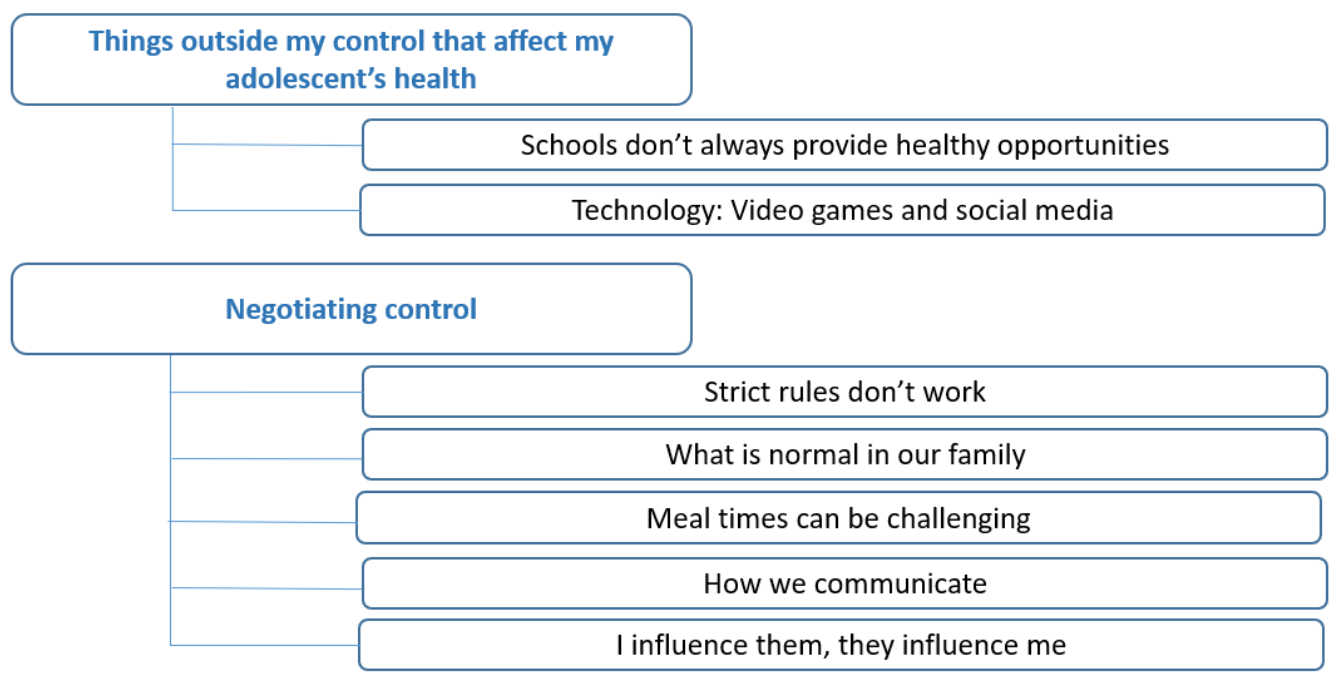

What parents think could help support adolescent health

How to target adolescents


628 Figure 2: Thematic map showing parents' perspectives of their role in supporting

629 adolescent health

630

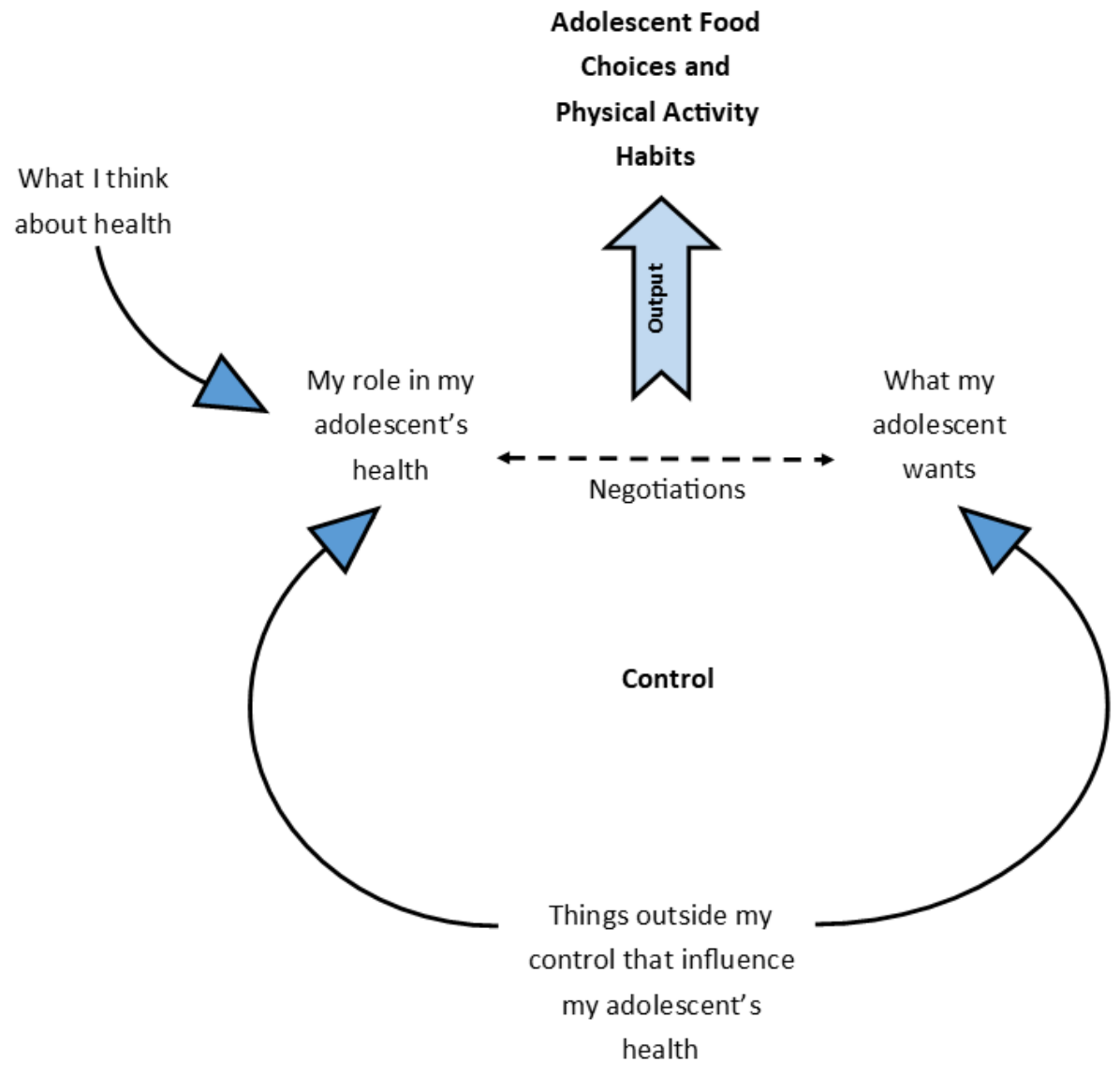

631

632

633 